DOI: $10.17951 /$ artes.2016.1.125

Dorota Zdunkiewicz-Jedynak

Uniwersytet Warszawski

d.jedynak@uw.edu.pl

\title{
Czy zagraża nam język popchrześcijaństwa? \\ O nowych zjawiskach w polskim dyskursie religijnym pierwszych dekad XXI wieku
}

Is the Language of Popular Culture a Threat to Christianity?

The New Phenomena of Polish Religious Discourse

in the First Decades of the Twenty-first Century

\begin{abstract}
Streszczenie: Komunikacja religijna nie pozostaje obojętna wobec komercjalizacji i homogenizacji kultury. Realizacji postulatu tzw. nowej ewangelizacji, by zanurzać dyskurs religijny w doświadczeniu człowieka XXI w., powinno towarzyszyć respektowanie ograniczeń w implementowaniu języka, gatunków i ikon popkultury do sfery komunikacji dotyczącej doświadczenia religijnego. W artykule zanalizowano takie wytwory współczesnej katolickiej kultury religijnej, jak internetowe memy ewangelizacyjne oraz przedmioty codziennego użytku (np. akcesoria kuchenne, ubrania), które służą jako nośniki treści religijnych, lub współczesne dewocjonalia i gadżety (np. wypisy biblijne w kształcie Biblii do żucia czy modlitewniki stylizowane na wyroby aptekarskie). Wskazano zagrożenia wynikające z dopasowania dyskursu religijnego do standardów popkulturowych i komercyjnych: uprawianie ewangelizacji w sposób intelektualnie niewymagający i czysto pragmatyczny nie prowadzi do duchowego rozwoju; nie czyni odbiorcy bardziej zdolnym do refleksji religijnej. Właściwa omówionym $\mathrm{w}$ artykule gatunkom wypowiedzi i zabiegom ewangelizacyjnym potoczna forma odbiera powagę treści tych przekazów. Umieszczenie treści religijnych w obszarze popkultury i komercji wprawdzie je upowszechnia, ale jednocześnie spłyca i zniekształca ich sens.
\end{abstract}

Słowa kluczowe: dyskurs religijny, komunikacja religijna, homogenizacja kultury, nowa ewangelizacja

Jednym z najważniejszych doświadczeń cywilizacyjnych Europy pierwszych dekad XXI w. jest konsumpcyjny styl życia, co skutkuje tym, że kultura dostosowuje się do reguł rynku - jej twórcy dążą przede wszystkim do zaspokojenia 
oczekiwań odbiorców - sprzyja to rozwojowi łatwej, niewymagającej refleksji rozrywki, najlepiej sprzedaje się bowiem to, co może być odbierane bez intelektualnego zaangażowania. Innym składnikiem tego doświadczenia, obok komercjalizacji kultury, jest jej homogenizacja.

Komunikacja religijna nie pozostaje obojętna wobec wymienionych zjawisk chrześcijanie na całym świecie wychodzą poza tradycyjne metody ewangelizowania, szukają sposobów, by uczestniczyć w wyścigu o istnienie w nowym świecie. Zdobywają więc nowych i utrzymują starych wyznawców, podporządkowując się wymogom współczesnej kultury wraz z jej wyróżnikami.

Jak może przebiegać realizacja nowoewangelizacyjnego ${ }^{1}$ postulatu zanurzania dyskursu religijnego we współczesnym doświadczeniu człowieka XXI w. i czy są respektowane jakieś ograniczenia w przenoszeniu języka, gatunków i ikon popkultury do sfery komunikacji dotyczącej doświadczenia religijnego? Jakie są możliwe zagrożenia wynikające $\mathrm{z}$ takich zapożyczeń i praktyk intertekstualizacyjnych? Takie pytania mogą dziś być stawiane nie tylko przez kulturoznawców i religioznawców, lecz także - ze względu na materię języka - przez językoznawców.

Na portalach internetowych stawiających sobie cele ewangelizacyjne, takich jak: www.ewangelizatory.pl, www.dayenu.pl, https://pl-pl.facebook.com/ romanszbiblia czy http://facebog.deon.pl/ i in., pojawiają się na przykład memy jako narzędzia ewangelizacyjne - publikowane na forach internetowych (a dalej rozpowszechniane za pośrednictwem Internetu) grafiki (także zdjęcia) opatrzone zwięzłym tekstem. Jest on komentarzem do warstwy ikonicznej przekazu, a jego treść ma charakter religijny. Społeczność internautów ukuła dla nich nawet nazwy - ewangelizatory czy chrystory.
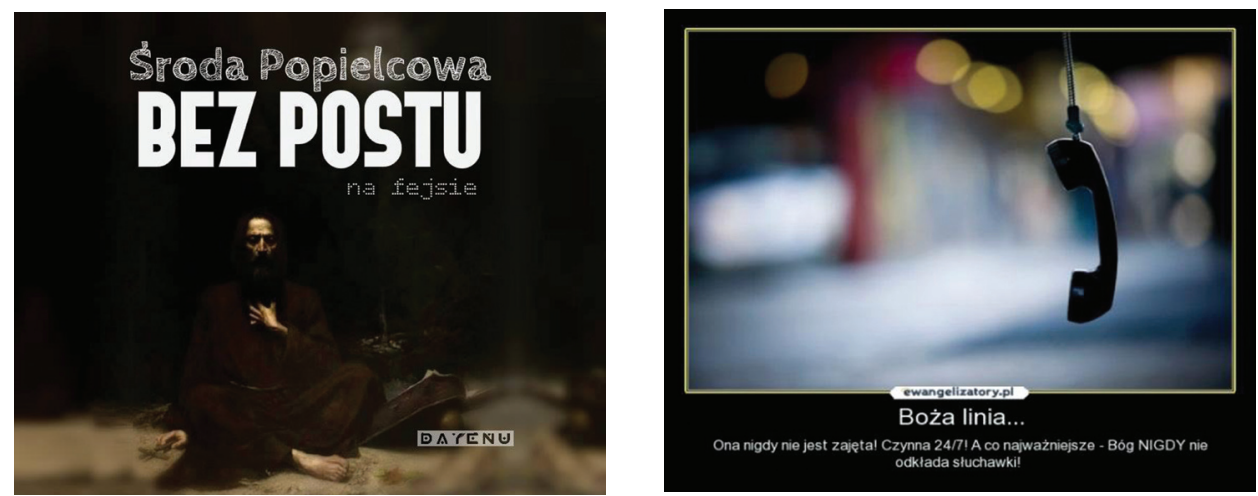

Idea odnowy języka w katolickim dyskursie religijnym sięga Soboru Watykańskiego II w jego programie aggiornamento, czyli dostosowania działań Kościoła do potrzeb epoki. 
Na uwagę zasługują takie spośród nich, które nie tylko wykorzystują ten gatunek internetowy - mem (co może nie jest jeszcze grzechem nowej ewangelizacji - w końcu popularność memów oraz ich wpływ na komunikację w ostatniej dekadzie jest nie do przecenienia, więc dlaczego nie mogłyby być wykorzystane także w sferze upowszechniania treści religijnych, jak dawniej w kulturze baroku czyniły to podobne do nich emblematy), lecz także sięgają przy tej okazji po standardy komunikacji popularnej, z takimi jej cechami, jak: powtarzalność, schematyczność, intelektualna płycizna, wreszcie - homogeniczność języka.

Rozbudowaną serię tworzą wśród nich na przykład te, które łączy wspólny element ikoniczny - postać Chrystusa stylizowanego na bohaterów filmów Disneyowskich. W taki obraz bywają wpisane różne napisy: „Chrześcijanin tańczy” (propagujący chrześcijańską postawę uwielbienia Boga); „Masz urodziny w Wigilię? Spoko, ja też!” (przypominający o Bożym Narodzeniu); „Nie wiesz co czytać? Moja biografia jest niezła!” (zachęcający do lektury Biblii); „Nie zasłużyłeś na moją miłość. Bo kocham Cię za darmo!” (mówiący o bezwarunkowej miłości Boga do człowieka).
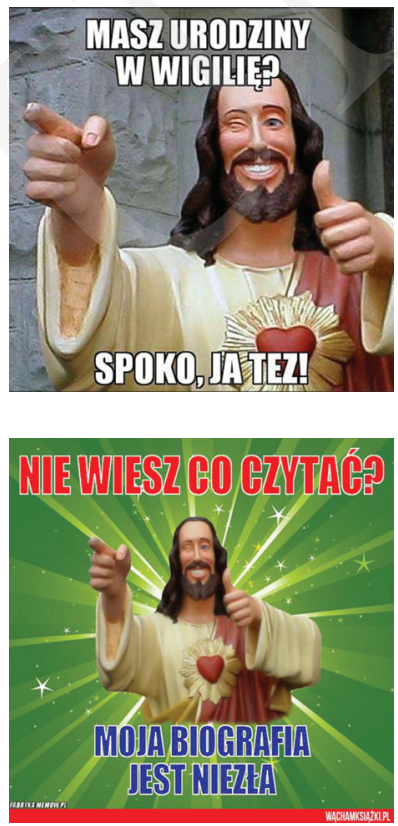
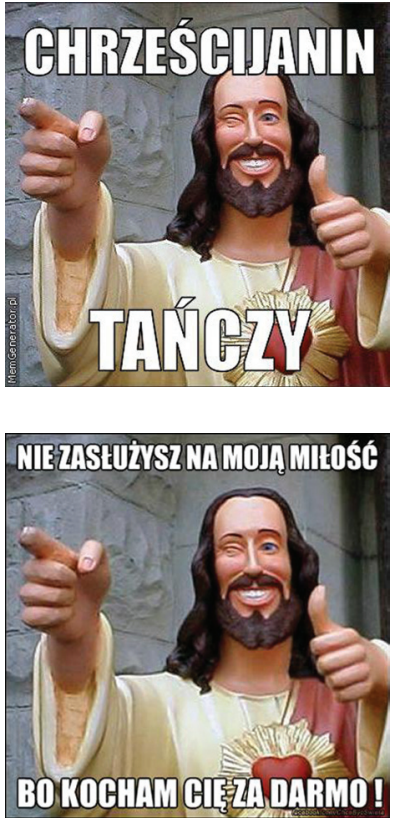

To jednak dopiero za pontyfikatu Jana Pawła II zrodziła się idea nowej ewangelizacji. Papież był jej orędownikiem, objaśniając jej sens w wielu homiliach oraz adhortacjach apostolskich i encyklikach. Jednym z najważniejszych postulatów było to, by głoszenie wartości ewangelicznych odbywało się z zastosowaniem nowych środków technicznych (i nowych mediów) oraz w języku zrozumiałym dla współczesnych, a więc zanurzonym w doświadczeniu i kulturze współczesnego człowieka. 
Warstwa werbalna w analizowanych memach zderza się z gestami mowy ciała (puszczone oczko mówi o sympatii, gest podniesionego kciuka symbolizuje w naszej kulturze sukces, zwycięstwo nad przeciwnościami losu lub miłe wydarzenie, wyciągnięty wskazujący palec w kierunku osoby - zwykle nam bliskiej - to poufały gest oznaczający swoiste zaproszenie interlokutora, zestawienie gestu obu rąk przywodzi na myśl także układ rąk właściwy sytuacji, gdy napinamy łuk, którego cięciwa jest skierowana na cel umieszczony naprzeciwko nas).

Popstylizacja warstwy ikonicznej jest łatwa do zauważenia w memach nawiązujących do produkcji filmowej Supermen, komiksowych postaci znanych przede wszystkim z różnych adaptacji telewizyjnych oraz kinowych, jak również gier komputerowych i innych towarów - Wojowniczych Żótwii Ninja, fikcyjnej postaci superbohatera Batmana (znanego z serii komiksowych oraz adaptacji filmowych związanych z tą postacią), fikcyjnej postaci komiksowej Spider-Mana, bohaterów amerykańskiego filmu animowanego Kung Fu Panda czy tytułowej postaci produkcji amerykańskiej kinematografii Stevena Spielberga - E.T. lub Osła z amerykańskiego filmu animowanego z 2001 r. Andrew Adamsona i Vicky Jenson - Shrek.
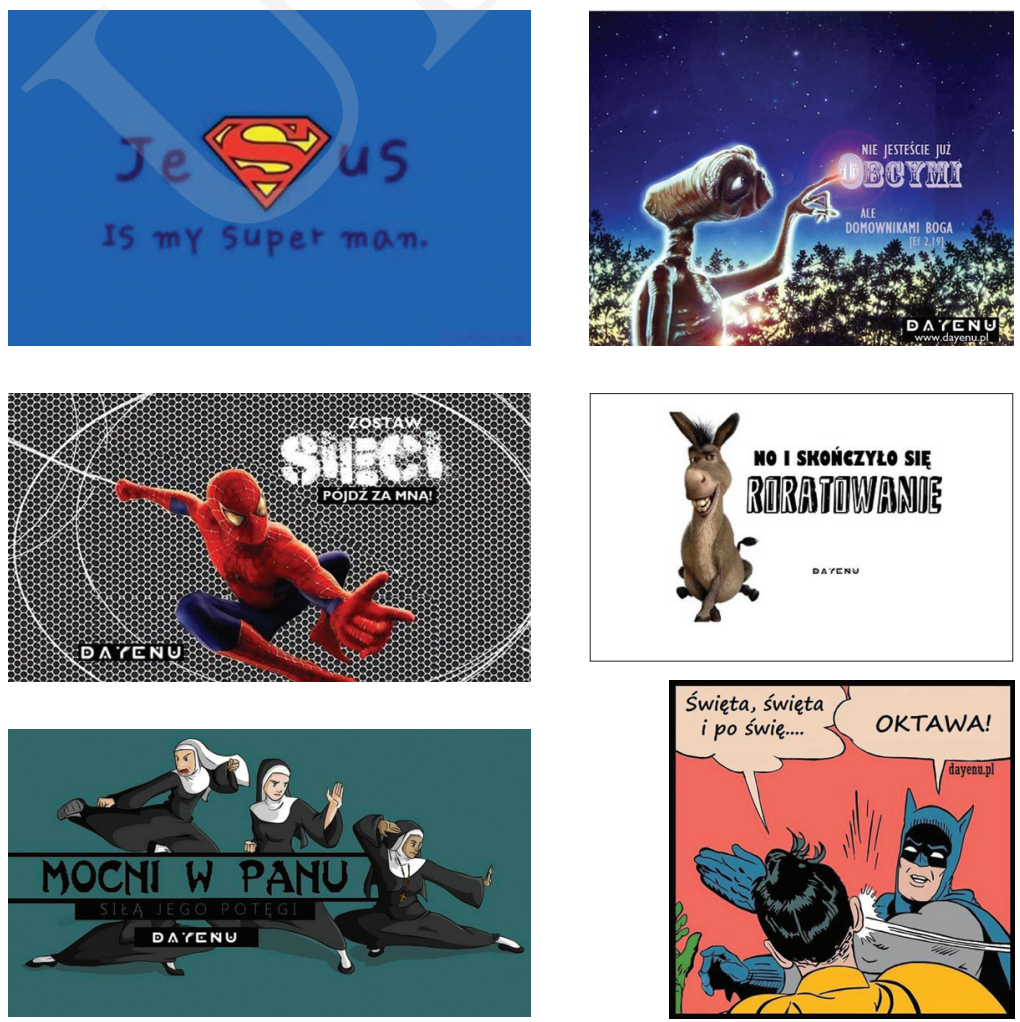
Z kolei mem promujący modlitwę Anioł Pański, odmawianą w południe, odwołuje się do tytułu kultowego filmu z 1952 r. Freda Zinnemanna, z Garym Cooperem - W samo potudnie - filmowej opowieści o stróżu prawa, który broni mieszkańców miasteczka przed rewolwerowcami.

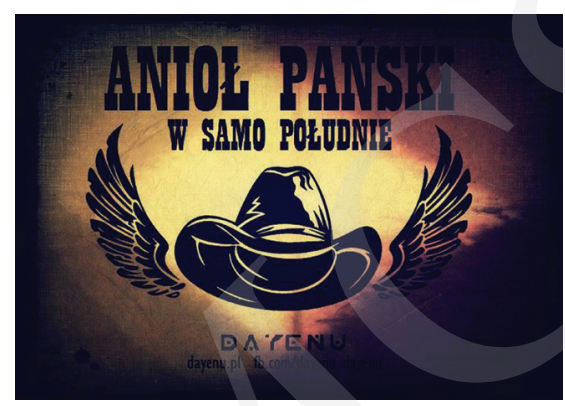

Odwołania do motywów znanych z mediów i do ich współczesnego języka nie należą do rzadkości. Tym sposobem posłużyli się twórcy memu przypominającego o Święcie Zwiastowania. Fragment historii Zbawienia - biblijną scenę zwiastowania Maryi przez Archanioła Gabriela - przedstawiono przez odesłanie do bytu właściwego współczesnej kulturze telewizyjnej i kinowej. Dziś bowiem przeciętny użytkownik polszczyzny z wyrazem „zwiastun” kojarzy nie tyle prognostyk jakiegoś wydarzenia czy posłańca, przynoszącego wieść o tym, co ma się wydarzyć, lecz przede wszystkim nadawaną w bloku reklamowym zapowiedź filmu albo programu, ewentualnie demo gry komputerowej, dostępne w Internecie lub na płycie dołączonej do czasopisma. Pierwsze skojarzenie jest zresztą wzmocnione $\mathrm{w}$ analizowanym memie przez użyte połączenie wyrazowe: „oglądać zwiastun”.

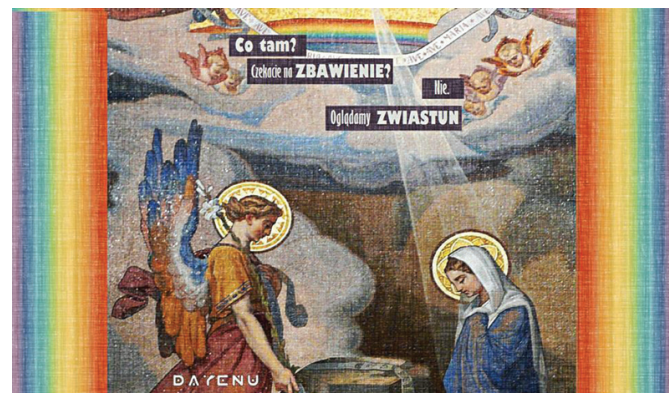

Część memów religijnych powstaje przez tworzenie kontaminacji wersetów biblijnych z treściami kultury popularnej. Umieszczanie cytatów z Biblii w nowym kontekście, zwłaszcza językowym (z intertekstualną grą polegającą na 
odesłaniu na przykład do tekstu reklamowego, popularnego przeboju disco polo czy potocznego skrzydlatego słowa) ma w założeniu ich twórców zdjąć z tekstu biblijnego patos, postrzegany jako skutkujący u odbiorcy dystansem, a nawet niechęcią do tej lektury. I tak, kryptocytat z Ewangelii św. Marka (10: 17: dosł.: „Nauczycielu dobry, co mam czynić, aby osiągnąć życie wieczne?”) umieszczono w kontekście nawiązującym do polskiego teleturnieju prowadzonego przez Tadeusza Sznuka „Jeden z dziesięciu” (opartego na brytyjskiej serii „Fifteen to One”).

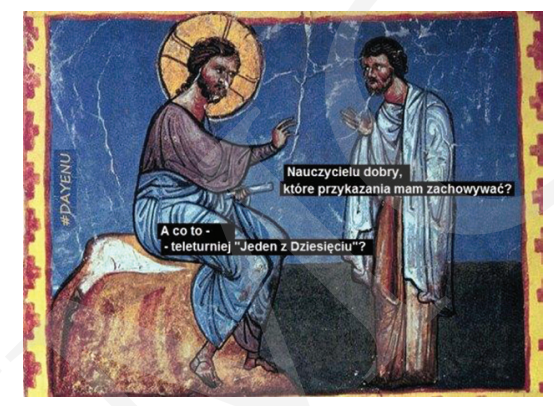

Werset zaś z 2. Listu do Koryntian: „Jeżeli już trzeba się chlubić, będę się chlubić z moich słabości” (2 Kor 11, 30), uzupełniono zdaniem: „Bo mam słabość do Boga", włożonym w usta gwiazdy filmowej - Rachel Weisz - i połączonym z obrazem przypominającym w warstwie ikonicznej reklamę biżuterii.

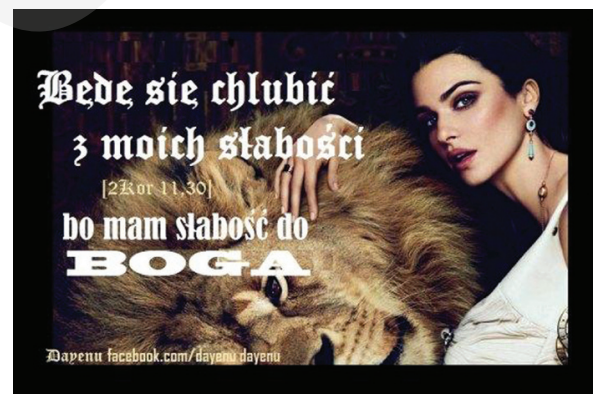

Nasuwa się obawa, że manifestowany w tym memie stosunek do Biblii zagraża właściwemu sensowi tej lektury. Niechcący pomniejsza jej wagę, wtłaczając w kontekst komercji i potocznego wyrażenia „mieć do czegoś słabość”. Wszak "mieć słabość" do kogoś to czuć jakąś irracjonalną sympatię do tej osoby. Takiej osobie pozwala się na więcej niż innym, trudniej odmawia jej prośbom, łatwiej się jej wybacza czy przymyka oko na to, co nam się w niej nie podoba. Gdy tak mówimy o stosunku do drugiego człowieka, mamy na myśli jakiś zauważany przez nas rozdźwięk między chłodną oceną rozumem a niekontrolowanym 
dyktatem uczucia. Słabość do przedmiotów z kolei (obrazów, perfum, samochodów) wiąże się z pewnym nieopanowanym pożądaniem ich posiadania. Wydaje się, że w chrześcijaństwie przecież nie o taki stosunek do Boga chodzi.

Przejawem zanurzenia dyskursu religijnego w kulturze popularnej jest mem, który odwołuje się do rozpowszechnionego w Polsce od lat 90. XX w. zwyczaju obcego polskiej kulturze i będącego świadectwem jej amerykanizacji, wykorzystywanego przez media i handel w celach komercyjnych - do walentynek.

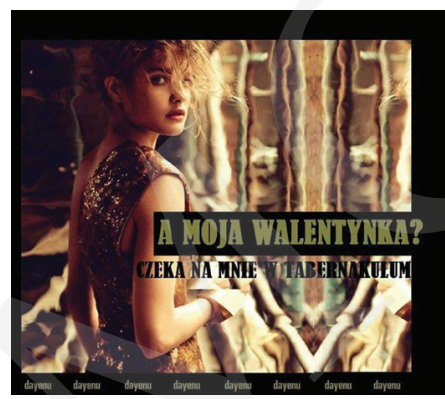

Jeden z memów ewangelizacyjnych stylizowany jest na okładkę amerykańskiego magazynu dla kobiet poświęconego modzie i stylowi życia - „Vogue”. Zamieszczono tu podobiznę włoskiej stygmatyczki - Gemmy Galgani. Przypisano jej przy tym tytuł "top model”; obraz dopełniono zaskakującym napisem: "Holy is the new sexy”.

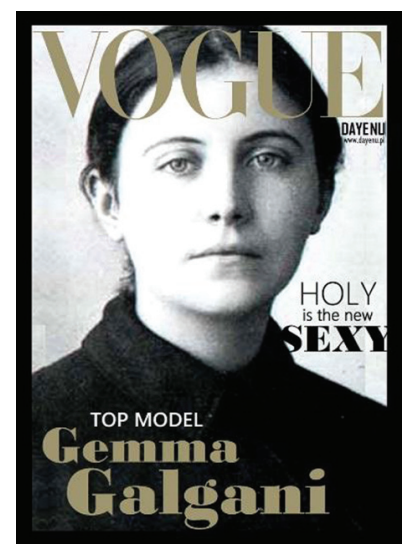

Do propagowania ewangelicznego ubóstwa wykorzystuje się obraz tak silnie zrośnięty z rzeczywistością komercyjną, jak karta kredytowa. Przypomnieniu zaś o praktyce kościelnej służy formuła graficzna zaproszenia na imieniny, na którym podobizna Jezusa przybiera kształt przystojnego mężczyzny, ubranego 
Pobrane z czasopisma Artes Humanae http://arteshumanae.umcs.pl

Data: 26/04/2023 08:41:50

według standardów modowych początku XXI w.: w T-shirt i dżinsy, z butelką piwa w jednej ręce i z drugą dłonią zawieszoną kciukiem na kieszeni spodni. Podobne gesty w mowie ciała sygnalizują zwykle zarozumiałość; palce użyte są $\mathrm{w}$ takim geście do okazania dominacji.
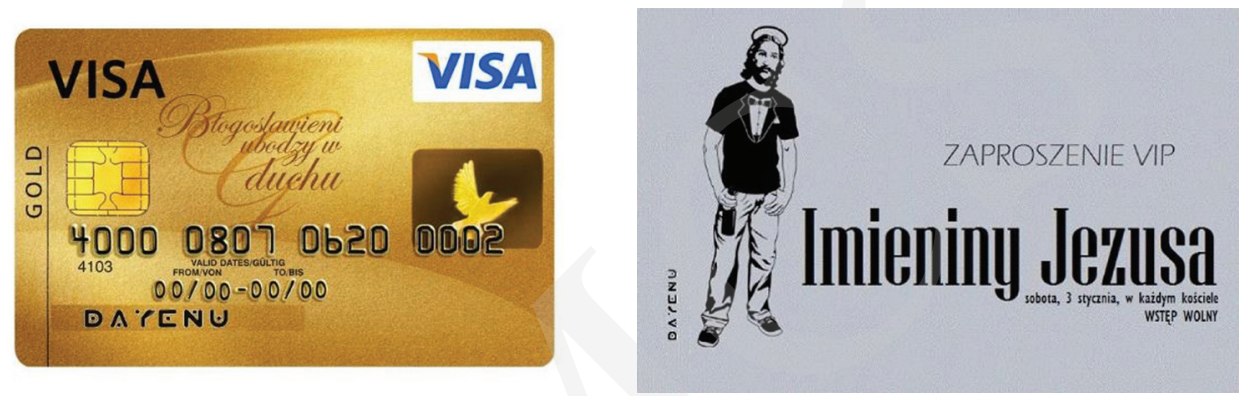

Wejście memetyki ewangelizacyjnej w sferę popkultury oznacza nie tylko odwoływanie się do jej gatunków i ikon, ale także do języka - potocznego, a nawet pospolitego, jeśli nie wulgarnego: Matka Boska w memie zachęcającym do modlitwy różańcowej to mama, na dodatek wystylizowana w sferze ikonicznej według współczesnego kanonu kobiecej urody.
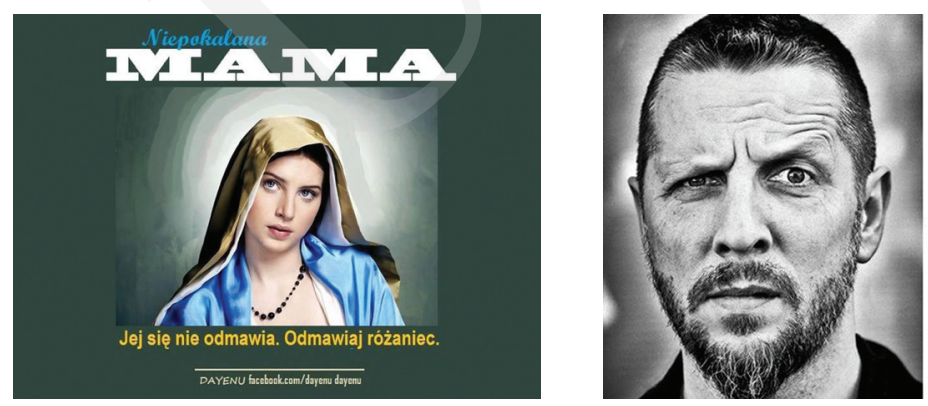

\section{[ ]}

Nawet największe gówno, Bóg może wykorzystać jako pożyteczny nawóz.

Robert "Litza” Friedrich

DATENU

\section{Hei bejbi,}

To co w tobie kręcimnie nojbardzie

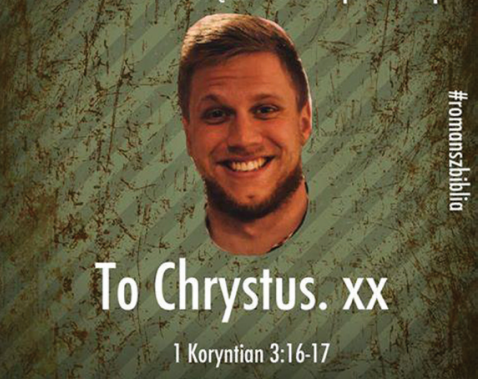


Słowo „Bóg” w memie dotyczącym niezbadanej mocy Bożej bez zahamowania jest użyte w bezpośrednim sąsiedztwie rzeczownika pospolitego "gówno”. O fascynacji Bogiem mówi się, używając czasownika potocznego „kręcić”, stosowanego zwykle w odniesieniu do osoby w kontekście pociągu fizycznego (por. „Ta dziewczyna mnie kręci”) albo w odniesieniu do rozrywek (por. kręci kogoś muzyka, alkohol, sport).

W imię idei uwspółcześnienia przekazu biblijnego rodzi się dziś także „katolicki design" ${ }^{2}$, promowany przez internetowe sklepy, np. www.sklepmalak.pl, http://www.sklep.deon.pl, www.bogwieco.com czy www.deyenu.pl. Sklepy te mają w swojej ofercie ubrania z aplikacjami w postaci cytatów biblijnych czy haseł ewangelizacyjnych, a także inne tekstylia, jak: torby i poduszki z nadrukami o treści religijnej.
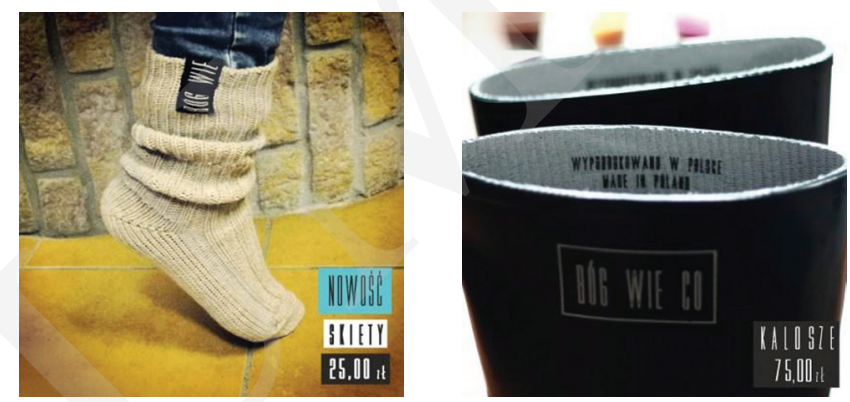

Jedna z koszulek przez widniejący na niej napis, choć nawiązuje do fragmentu biblijnego mówiącego o budowaniu na skale, przypomina reklamę dewelopera: „Domy na Skale. Dożywotnia gwarancja przetrwania każdej burzy”. Inna - stylizowana jest na firmową koszulkę reklamującą uczelnię: „Uniwersytetu Dobrego Nauczyciela".
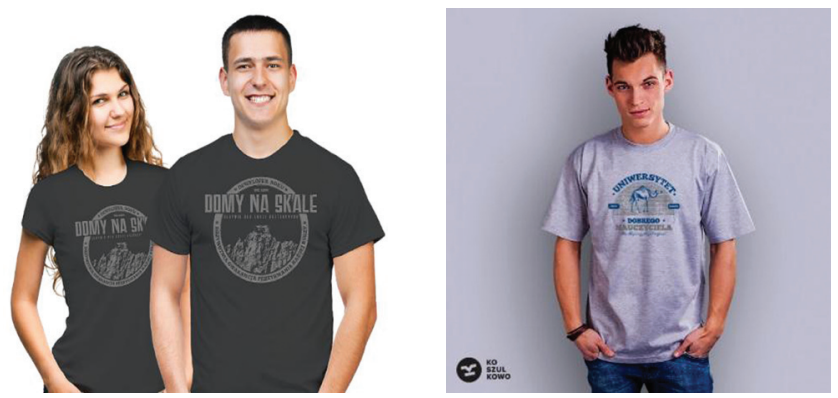

2 Na ten temat można przeczytać więcej, np. w „Gazecie Wyborczej” i w miesięczniku „W Drodze” (por. Rachid-Chehab 2014; Strzelczyk 2014; Karabin 2014). 
W internetowym sklepie rokokoko.pl można także kupić torbę z cytatem z Ewangelii Łukaszowej: „Mamy tylko 5 chlebów i dwie ryby, chyba że pójdziemy i nakupimy żywności", a sklep na stronie internetowej www.sklepmalak.pl proponuje torbę z napisem: „Jak Boga kocham”. Idea ekumenizmu jest propagowana na stronie sklepu www.dayenu.pl przez torbę z wizerunkiem zakonnicy stylizowanej na matrioszkę i napisem z potocznym czasownikiem „schizować”: „Nie schizuj! Módl się o jedność”.
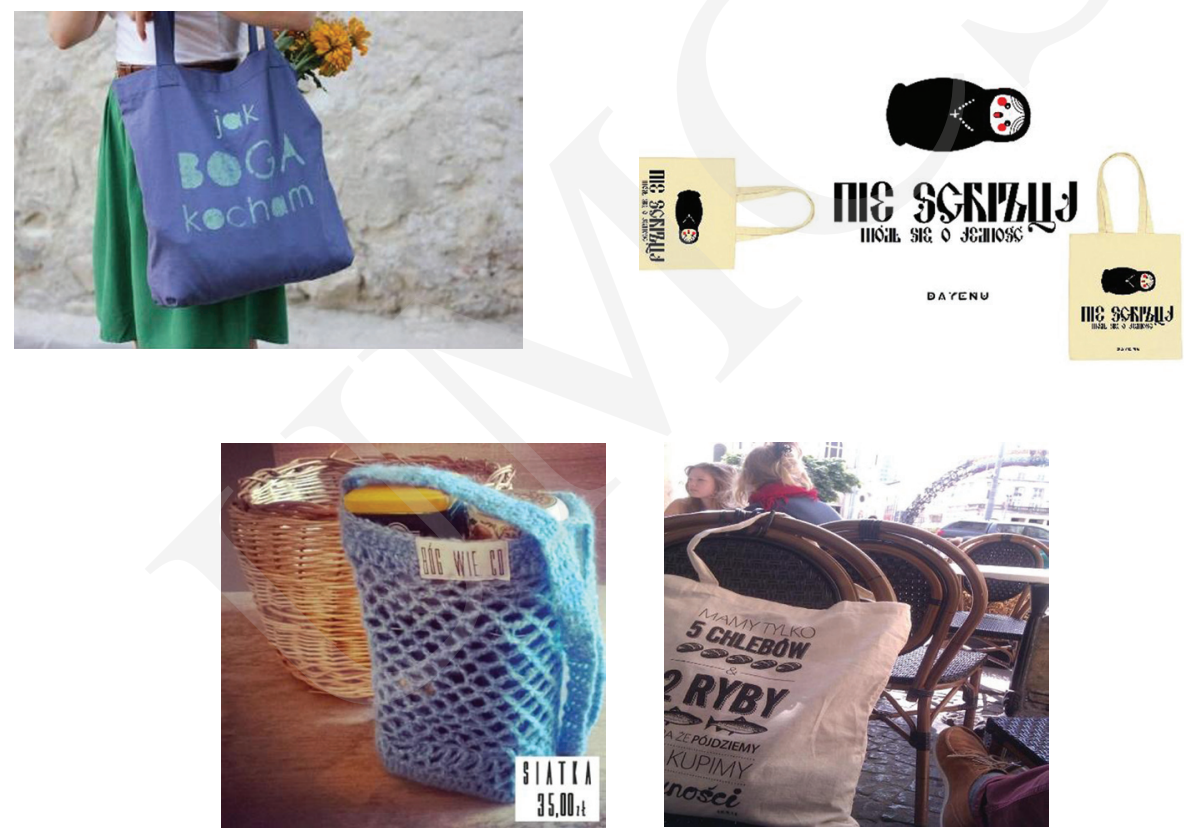

Wyrażenia typu „Bóg wie co” czy „jak Boga kocham” umieszczane na przedmiotach codziennego użytku mają - w założeniu twórców - stać się wyznaniem wiary, rodzajem aktu strzelistego, a nie pozostawać tylko sfrazeologizowanymi ekspresywnymi formami językowymi. Czy tak jednak rzeczywiście się staje?

Nośnikami wyrażonej werbalnie treści religijnej stają się dziś przedmioty codziennego użytku, jak akcesoria kuchenne (np. podkładki kuchenne, solniczki, kubki, naklejki na słoiki z przetworami itp.), także gry online i gry planszowe czy puzzle.

Puzzle są reklamowane na stronie www.dayenu.pl na wzór gier rozrywkowych jako "gra dla ludzi o mocnych nerwach" - ułożone puzzle tworzą bowiem obraz przedstawiający męczeństwo polskiego biskupa - św. Stanisława. 
Pobrane z czasopisma Artes Humanae http://arteshumanae.umcs.pl Data: 26/04/2023 08:41:50
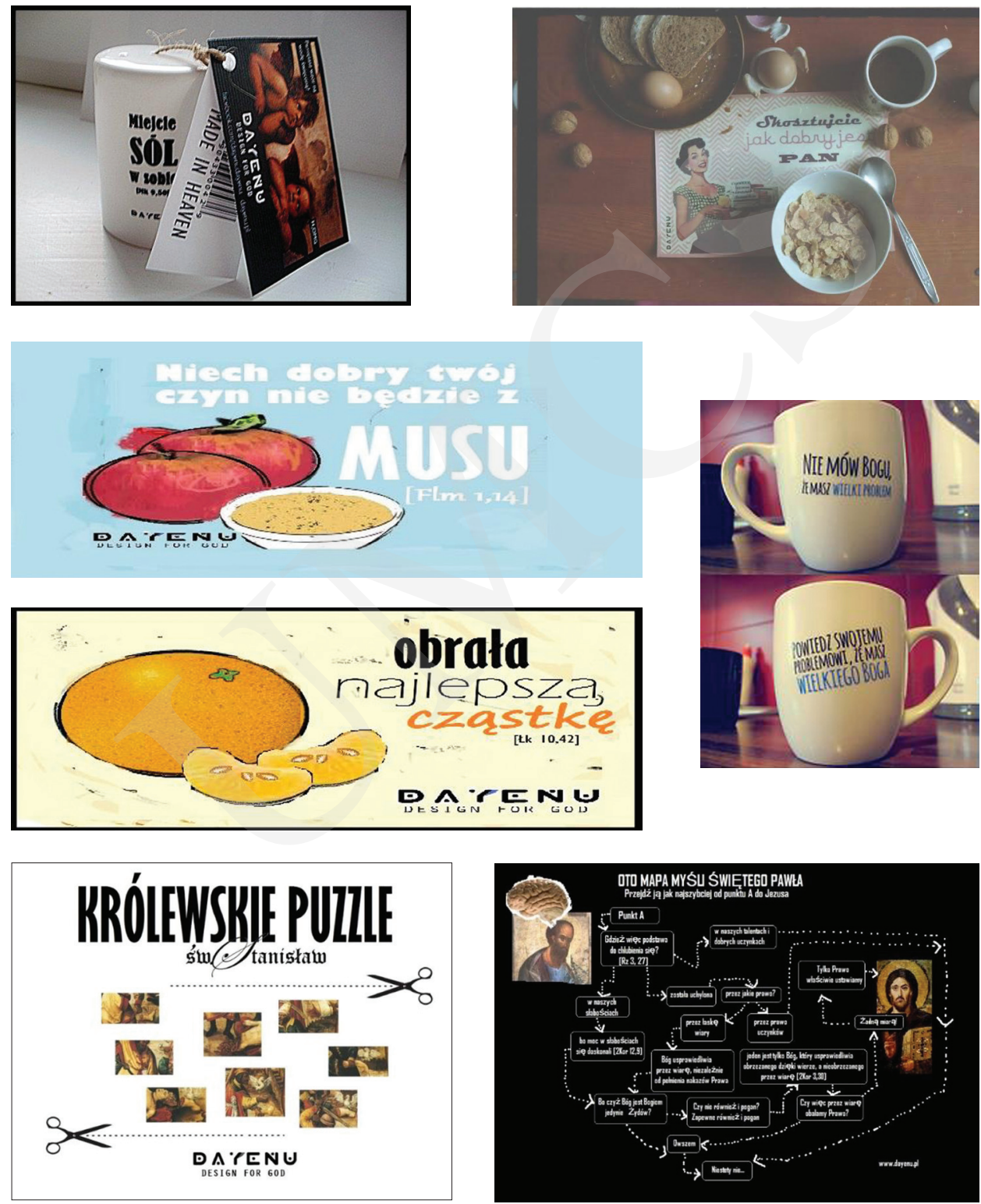

W ofercie sklepów internetowych rośnie liczba przedmiotów paraużytkowych. Wśród nich znajdujemy na przykład huśtawkę ze skrzydłami czy samoprzylepne, transparentne tatuaże, np. ze znakiem „Płukać w krwi Baranka”). 

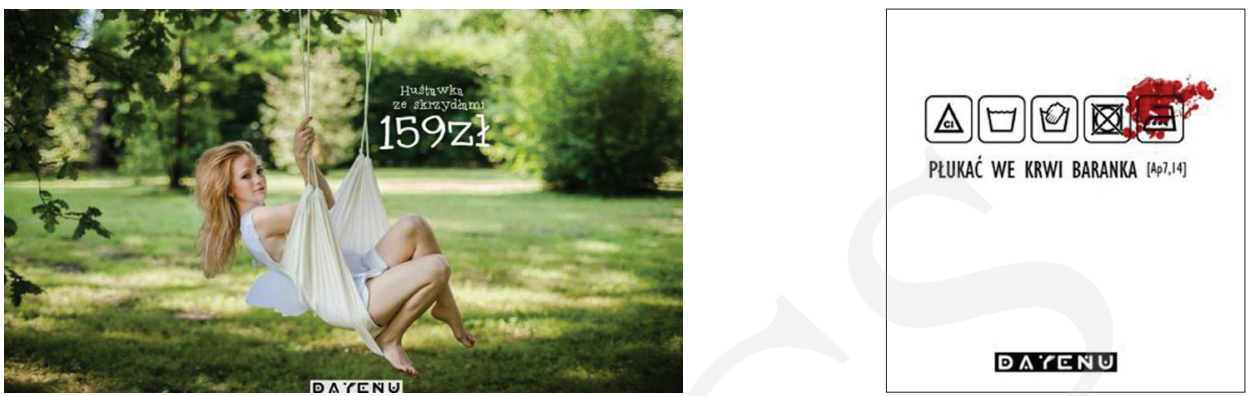

Wśród religijnych gadżetów uwagę zwraca promująca codzienną lekturę Biblii „Biblia do żucia” w kształcie paczuszki z gumą do żucia. W opakowaniu umieszczono 30 listków z zapisanymi fragmentami biblijnymi.

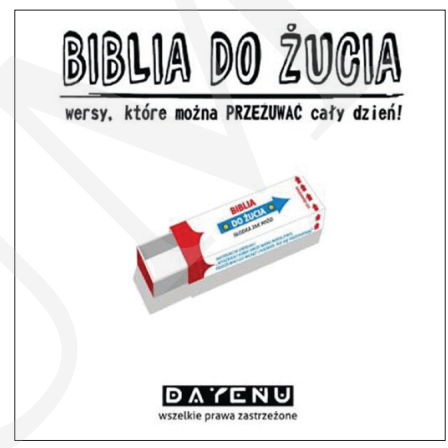

Zachęta do praktykowania codziennej lektury biblijnej stylem przypomina z jednej strony instrukcje, jakie można znaleźć w opakowaniu sprzętów codziennego użytku domowego, z drugiej - ulotki leków. Na stronie sklepu czytamy:

Wygląda jak guma, smakuje jak miód. BIBLIA DO ŻUCIA to zbiór 30 najważniejszych wersów z najważniejszego kazania Jezusa Chrystusa, po jednym do rozważania na każdy dzień miesiąca. Noś zawsze przy sobie, stosuj systematycznie, częstuj znajomych i nieznajomych [...]. Przed zastosowaniem koniecznie zapoznaj się z instrukcją obsługi dołączoną do opakowania. BIBLIA DO ŻUCIA powoduje szereg skutków ubocznych, a przy częstym stosowaniu mocno uzależnia. Polecamy ją jednak młodzieńcom i starszym, kobietom w ciąży i dzieciom, osobom chorym, samotnym, zagubionym, smutnym i znudzonym życiem. Bez ograniczeń! 100\% łaski! [...] "Uwaga! Produkt nadaje się jedynie do spożycia w sensie duchowym! Nie jeść! Nie karmić zwierząt! 
Miejsce tradycyjnego modlitewnika, według pomysłu Gdańskiego Seminarium Duchownego, zajmuje Misericordyna (59 granulek dosercowych) - wyrób stylizowany na opakowanie medykamentu.

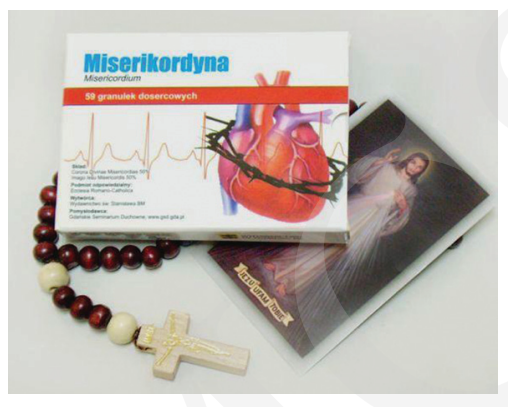

Cały zestaw zawiera: różaniec, obrazek z Jezusem Miłosiernym i ulotkę informacyjną sporządzoną według reguł gatunkowych i wymogów stylistycznych ulotki informacyjnej o leku, w której informacje są uporządkowane według stałego schematu kompozycyjnego:

1. Co to jest Misericordyna i w jakim celu się ją stosuje;

2. Zanim zastosujesz lek;

3. Jak stosować lek?;

4. Sposób podawania leku;

5. Możliwe działania niepożądane i przeciwwskazania (tu wskazówka, że „można stosować z innymi modlitwami oraz stosowanie sakramentów świętych sprzyja działaniu duchowemu");

6. Inne informacje.

Na opakowaniu dodatkowo uwidoczniono skład procentowy z zapisem łacińskim: Corona Divinae Misericordiae 50\%, Imago Iesu Misericordis 50\%.

W „internetowej aptece” można znaleźć wiele podobnych „produktów leczniczych": Via Crucis. Panaceum forfte („duchowe antidotum na stany strapienia, smutku i choroby, z którymi zmaga się ludzka dusza, ale też i ciało".

„Lek - według informacji z ulotki - pomaga w ufnym poszukiwaniu Boga, a także przywraca wiarę w trudnych chwilach, które przeżywa osoba smutna lub chorująca. Jak wykazały badania, zażywanie tego lekarstwa wpływa korzystnie również na serce człowieka i panujące w nim uczucia".

Opakowanie zawiera Rozważanie drogi krzyżowej, Koronkę do siedmiu boleści Matki Bożej) oraz Spiritualis Unctio. Mocne lekarstwo duchowe (,antidotum na duchową oziębłość", które „przeciwdziała słabościom, wzmacnia wiarę i dodaje sił"). Pudełko zawiera:

1. Modlitewnik Duchu Święty uświęć mnie; 


\section{Koronkę do Ducha Świętego;}

3. Ulotkę zawierającą tekst Koronki i sposób jej odmawiania.

Także inne produkty podobnego charakteru - Antydepresol, Kocham Cięforte, Pocieszalina - są wystylizowane w sferze graficznej na medykamenty, a w sferze językowej - na ulotki informacyjne o leku.
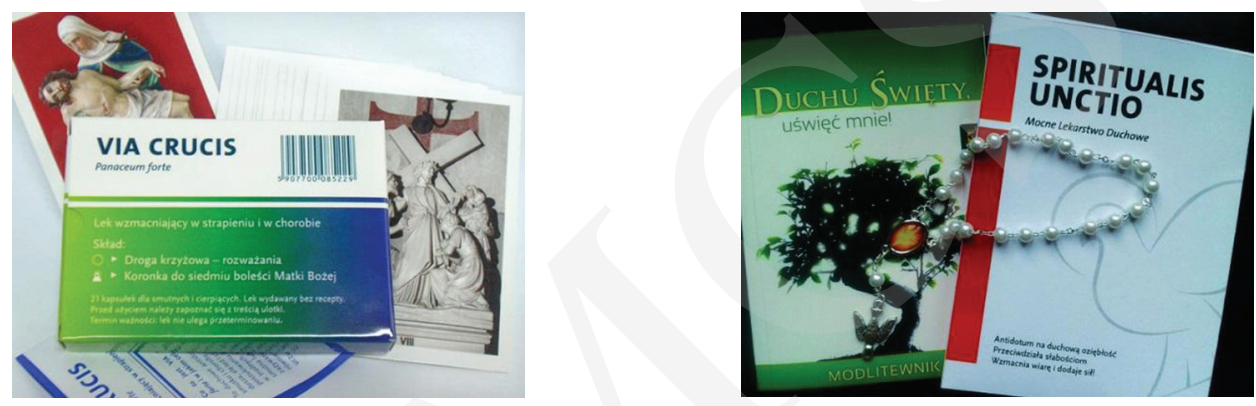

Na koniec jeszcze wspomnijmy jeden przykład inicjatywy ewangelizacyjnej, która pokazuje, jak coraz silniej w dyskursie dotyczącym treści religijnych dają o sobie znać praktyki intertekstualizacyjne, które zacierają - dotąd ostre - granice między dyskursem religijnym i dyskursem popkultury. Chodzi o pomysł Kamila Szumotalskiego i Jakuba Kiersikowskiego, którzy w 2014 r. zaproponowali cykl internetowych rekolekcji Postman ${ }^{3}-7$ wideokomentarzy zamieszczanych w Wielkim Poście w sieci do niedzielnych czytań ewangelicznych. Całość jest utrzymana w konwencji programów komercyjnych stacji radiowych, mocno kolokwialna w sferze języka.

W kontekście omówionych przykładów implementacji języka i gatunków popkultury w komunikacji religijnej rodzą się wątpliwości co do ceny posługiwania się nimi jako narzędziem mówienia o doświadczeniu religijnym i upowszechniania treści religijnych. Ich dopasowanie do standardów popkulturowych i komercyjnych - a w konsekwencji uprawianie ewangelizacji w sposób powierzchowny, intelektualnie niewymagający i czysto pragmatyczny nie służy chyba wymagającemu zaangażowania intelektualnego duchowemu rozwojowi; nie czyni odbiorcy bardziej zdolnym do refleksji w ogóle, nie mówiąc o refleksji religijnej. Właściwa podobnym gatunkom wypowiedzi i zabiegom ewangelizacyjnym potoczna forma odbiera powagę treści tych przekazów. Decydując się w komunikacji

3 Dostępne na stronie projektu Ewangelizacja waw.pl, pod adresem: https://www.youtube. com/channel/UCw0yW6iA_KWo54_Ym0KacoA (dostęp: 12 września 2015). 
religijnej na odwołania intertekstualne do sfery języka i gatunków popkultury, warto zawczasu uczynić rachunek możliwych zysków i strat; pamiętać, że umieszczenie treści religijnych w obszarze popkultury i komercji wprawdzie je upowszechnia, ale jednocześnie bezpowrotnie spłyca i zniekształca ich sens.

\section{Bibliografia}

1. Rachid Chehab Milena, 2014, Nowy design katolicki, czyli dewocjonalia, „Gazeta Wyborcza” 12.07.2014, http://wyborcza.pl/1,75475,16312237,Nowy_design_katolicki__czyli_dewocjonalia_tez_moga.html\#ixzz3SaNnKeqI (dostęp: 22 lutego 2015).

2. Strzelczyk Błażej, 2014, Katolicki disign czy wspótczesny look, http://natemat. pl/73507,katolicki-design-kicz-czy-wspolczesny-look (dostęp: 22 lutego 2015).

3. Karabin Ewa, 2014, Katolicki beż, „W Drodze”, nr 5, http://www.wdrodze.pl/miesiecznik/index.php?mod=archiwumtekst\&id=15237\#.VOyrWprxJy0 (dostęp: 22 lutego 2015).

4. Small Gary W., Vorgan Gigi, 2011, iMózg. Jak przetrwać technologiczna przemianę wspótczesnej umystowości, tłum. Sy Borg, Poznań: Vesper.

\section{Źródła grafik}

1. http://pruszcz.diecezjagda.pl/fotogaleria/ewangelizatory (dostęp: 25 października 2015).

2. www.ewangelizatory.pl (dostęp: 25 października 2015).

3. www.dayenu.pl (dostęp: 25 października 2015).

4. http://www.ichtis.pl/misericordina-misericordium (dostęp: 25 października 2015).

5. http://www.sklep.deon.pl (dostęp: 25 października 2015).

6. www.bogwieco.com. (dostęp: 25 października 2015).

7. www.rokokoko.pl (dostęp: 25 października 2015).

Summary: Religious communication doesnt remain indifferent to commercialization and homogenization of culture. The new evangelizations aim to adjust religious discourse to the $21^{\text {st }}$ century mans experience should respect restrictions in the implementation language, genres and icons of pop culture to religious communication. In the paper the author is analysing products of contemporary Catholic religious culture, such as Internet evangelizing mems and everyday articles (e.g. kitchen accessories, clothes, which serve as means of conveying religious contents) or contemporary devotional items and gadgets (e.g. biblical excerpts in shape of "chewing Bible" or prayer books similar to pharmaceutical products). The author shows threats standing behind 
Pobrane z czasopisma Artes Humanae http://arteshumanae.umcs.pl

Data: 26/04/2023 08:41:50

fitting religious discourse to pop culture and commercial standards: practising of evangelization in an intellectually not demanding and pragmatic way wont result in spiritual development. Introducing religious content into the popular cultures context may promote it, but it also distorts it.

Key words: religious discourse, religious communication, homogenization of culture, new evangelization 